\title{
HIV Infection among Under-Five Malnourished Children in Kano State
}

\author{
A. Sudawa ${ }^{1 *}$, A. A. Ahmad ${ }^{2}$, S. Adeleke ${ }^{3}$, L. Umar $^{4}$, L. D. Rogo $^{5}$ \\ ${ }^{1}$ Nigeria Field Epidemiology and Laboratory Training Programme, Abuja, Nigeria; ${ }^{2}$ Department of Microbiology, Faculty of Sci- \\ ences, Ahmadu Bello University, Zaria, Nigeria; ${ }^{3}$ Department of Paediatrics, Teaching Hospital Gwagwalada, Abuja, Nigeria; \\ ${ }^{4}$ Department of Paediatrics, Ahmadu Bello University Teaching Hospital, Zaria, Nigeria; ${ }^{5}$ Department of Medical Laboratory Sci- \\ ence, Faculty of Medicine, Bayero University, Kano, Nigeria. \\ Email: *draminusudawa207@yahoo.com
}

Received August 22 $2^{\text {nd }}, 2013$; revised September $22^{\text {nd }}, 2013$; accepted September $29^{\text {th }}, 2013$

Copyright (C) 2013 A. Sudawa et al. This is an open access article distributed under the Creative Commons Attribution License, which permits unrestricted use, distribution, and reproduction in any medium, provided the original work is properly cited.

\begin{abstract}
Objective: Human Immunodeficiency Viral infection and Protein Energy Malnutrition (PEM) are highly prevalent in Nigeria and when they occur together, the outcome is usually severe as both conditions lead to immune suppression. HIV alone accounts for $14.0 \%$ of childhood mortality even though children constitute only $6 \%$ of global HIV infection burden. The objective of the study was to determine the prevalence of HIV infection among malnourished children below 5 years in Kano State, Nigeria. Methods: A total of 400 malnourished children were randomly selected and tested for the presence of HIV I \& II using parallel ELISA rapid test kits, Stat park and Determine (both immunochromatographic techniques). Findings: Thirty-one samples were found to be positive to HIV 1 giving a prevalence of $7.8 \%$. There was no statistically significant difference between sexes when male to female ratio was 1:1.3 and peak age of presentation was 2 - 3 years. Sixty-four percent $(64.0 \%)$ were presented with severe form of HIV infection (stage 4) according to WHO paediatric HIV clinical stage and about half of them came with marasmus by the Wellcome classification of malnutrition. There was no significant association between the type of malnutrition and the severity of HIV infection at present, ( $\mathrm{p}$ value $>0.05$ ). The commonest signs and symptoms were oral candidiasis $(67.7 \%)$, lymphadenopathy $(44.0 \%)$, fever $(64.5 \%)$ and cough $(54.8 \%)$. Sixty-four percent of the children were from polygamous families. There was a significant statistical correlation between polygamy and incidence of HIV infection, $(\mathrm{p}<0.01)$. Only $45.0 \%$ of the women were aware of their HIV status prior to this study. Seventy-four percent $(74.0 \%)$ of those who were aware of their status had no knowledge of the prevention of mother to child transmission (PMTCT) services and even for those who were aware, none of them accessed the care. Conclusion: A population based HIV screening is therefore recommended while perinatal HIV screening and PMTCT services need to be expanded.
\end{abstract}

Keywords: Human Immunodeficiency Virus; Protein Energy Malnutrition; Children; Oral Candidiasis; Lymphadenopathy

\section{Introduction}

Human Immunodeficiency Virus (HIV) is a member of Lentivirus genus, Retroviridae family (slowly replicating retrovirus) that causes acquired immunodeficiency syndrome (AIDS), a condition in humans in which progressive failure of the immune system allows life-threatening opportunistic infections and cancers to thrive $[1,2]$. Paediatric HIV infection is a growing health challenge worldwide with an estimated 1500 new infections every day [3]. According to UNAIDS report, about 2.5 million

${ }^{*}$ Corresponding author. children under the age of 15 were living with HIV/AIDS in 2007 and 330,000 died of AIDS. The report added that about 420,000 new infections have occurred in the same year among children aged below 15 years. More than 95\% of HIV infected infants in Africa acquire the infection from their mothers during pregnancy, at the time of delivery, or postnatally through breastfeeding [4]. Studies from Federal Capital Abuja reported mother to child transmission at $(93.02 \%)$, blood transfusion $(4.6 \%)$ and unidentified route (2.3\%) [5]. Reports from Zaria, NorthWestern Nigeria showed vertical transmission of $88.6 \%$, blood transfusion $8.6 \%$, and unknown routes $2.8 \%$ [6]. 
About $30 \%$ vertical transmission and blood transmission of $68 \%$ mostly among sickle cell paediatric patients were reported from Enugu-Eastern Nigeria [7]. These figures indicated an improvement in the area of blood screening over the decade. However, the rate of mother to child transmission of HIV varies by geographical location. The overall risk of mother to child transmission (MTCT) without intervention is $15 \%-30 \%$ in Europe and USA [3]. Rates of 30\% - $40 \%$ of MTCT have been reported in African countries [4]. A transmission rate of $45 \%$ was found in a study conducted at UCH Ibadan [8].

Vertical transmission of HIV and the effects of the virus on an immature immune system undoubtedly influence disease expression in ways that are yet poorly defined. Without treatment, HIV infected children in developing countries have mortality rate of $45 \%-59 \%$ by two years of age compared to $10 \%-20 \%$ in Europe and USA [3]. Mortality as high as $92.8 \%$ below the age of two years among HIV infected children has been reported [8]. Factors that contribute to this difference include a higher rate of other infections, malnutrition and deficiency of macronutrients in developing countries compared to developed countries.

There are limited data on clinical and biological indicators of disease progression in HIV infected children in Africa. Some reports and clinical experience indicate that children perinatally infected with HIV fit into one of three categories: about $25 \%-30 \%$ are the rapid progressors who die by age of one year and are thought to have acquired infection in utero or during early perinatal period. Children who develop symptoms early in life, followed by a downhill course and death by age three to five years constituting about $50 \%-60 \%$ form the second category. The remaining $5 \%-25 \%$ are the third category, the long-term survivors, who live beyond eight years [4].

The impact of high poverty level endemic in Nigeria and North Western zone in particular, leading to high incidence of malnutrition among children could be portrayed lower than the actual prevalence rate of HIV infection among the study population. Another new dimension in the epidemiology of severe PEM in sub-Saharan Africa is the creation of a large pool of Aids related orphans [9]. There is estimated $1-1.5$ million AIDS related orphans in the sub-Saharan Africa. These children, whose parents died of AIDS, are often uncared for by their relations and government, and they are highly susceptible to malnutrition. This has a highly significant impact on AIDS in childhood malnutrition in Africa. Psychosocial issues can lead to inadequate nutrition due to limited food supply resulting from financial difficulties. Parents may be too ill or disinterested to care for themselves and their children due to HIV infection [10]. Therefore the aim of this research is to study HIV infection in under-five malnourished children in Kano State.

\section{Materials and Methods}

\subsection{Study Area}

The study was conducted in Kano State located in the north-western part of Nigeria on $12^{\circ} \mathrm{N}$ latitude and $9^{\circ} 20^{\prime} \mathrm{E}$ longitude. Kano is one of the commercial centers of Nigeria and has the largest population of 9,383,682 million people according to the National Population Commission census figures of 2006. Islam is the dominant religion in the State which is practiced by about $99 \%$ of the populace and the major tribes are Hausa and Fulani.

The State comprises of 44 Local Government councils which are divided into three Senatorial districts i.e. Kano Central, Kano North and Kano South. The Kano Central comprises of 14 Local Governments and it harbors about $50 \%$ of the entire population. There are a total of 26 general hospitals spread across the state, and several Primary Health Care centers and health posts which are under the control of their respective local governments council.

\subsection{Sampling and Methods}

This is a multi-centered hospital based cross-sectional study. Children below the age of 5 years who came with malnutrition were consecutively selected from the selected hospitals after getting consent from their mothers. Sample size was approximated to 400 . Considering the population distribution in the state half of the samples (200) was taken from Kano central senatorial district and 100 samples each from the north and south senatorial districts. In each study location, half of the study population was taken from out-patient clinic and the other half from in-patients.

Dry sterile plastic syringe $(2 \mathrm{ml}$ capacity) with 23SWG needle attached to was used for blood collection. Blood was collected by applying soft tubing tourniquet on the arm of the patient to enable the veins to be seen and felt. The site was cleaned using methylated spirit and allowed to air dry. The needle was inserted to the selected straight vein with the bevel of the needle directed upward in the line of the vein. Steadily the plunger of the syringe was withdrawn until $2 \mathrm{ml}$ of blood was obtained. The tourniquet was loosed and the needle was removed from the punctured vein. Pressure was applied to the punctured site to secure haemostasis. The needle was removed from the syringe and the blood was transferred to a clean dry plain specimen bottle and labelled. The used syringes and needles were disposed appropriately. The blood samples were centrifuged at 1500 revolution per minute for five minute $(1500 \mathrm{rpm} / \mathrm{min}$ for $5 \mathrm{~min})$ with model 80 - $1 \mathrm{~B}$ centrifuge machine and the serum collected into a clean and dry plain specimen bottles using clean and dry Pasteur pipettes and stored at $-20^{\circ} \mathrm{C}$ until needed for analysis [11]. 
Parallel tests were run using Stat-Pak Assay test kit (Chembio Diagnostic Systems, Medford New York, USA) and Determine (Abbott Japan Co. Ltd.). After allowing the serum to come to room temperature and about $5 \mu \mathrm{l}$ is dispensed onto the centre of the sample(s) well and the test result read after 10 minutes. Same process is repeated on the sample using Determine kit according to the manufacturer's instruction.

\section{Results}

A total of 400 samples were collected and analyzed for the presence of HIV I \& II using two parallel tests, that is Stat park and Determine park. Thirty one (7.8\%) samples were found to be positive to HIV. No single case of discordance was recorded between the two Eliza test kits used in the study. Mode of transmission was vertical in all cases. Table 1 shows prevalence rate of HIV among malnourished children attending selected hospitals in Kano State and the prevalence in all the three geo-political areas in the state. The state wide prevalence among the study population is $7.8 \%$ while a prevalence rate of $13.0 \%, 4.0 \%$ and $1.0 \%$ was recorded for Kano central, Kano South and Kano North respectively.

Table 2 shows age distribution among the HIV positive children. The peak age presentation is $2-3$ years which accounts for $52 \%$. The male to female ratio was $1: 1.3$.
Table 3 shows type of malnutrition at presentation among the HIV positive children according to wellcome classification of malnutrition. Fifteen children presented with marasmus, 10 with marasmic-kwashiorkwor, four with kwashiorkwor and two were underweight.

Table 4 shows percentage of seropositivity in all the

Table 1. Prevalence rate of HIV among the malnourished children in Kano State and in each geo-political area.

\begin{tabular}{cccc}
\hline Geopolitical area & No. Tested & No. positive & \% positive \\
\hline Kano central & 200 & 26 & 13.0 \\
Kano south & 100 & 4 & 4.0 \\
Kano north & 100 & 1 & 1.0 \\
Total & 400 & 31 & $7.8 \%$ \\
\hline
\end{tabular}

Table 2. Age and sex distribution among HIV positive children.

\begin{tabular}{cccc}
\hline Age group (months) & Males & Females & $\begin{array}{c}\text { \% sero-positvity in } \\
\text { each age group }\end{array}$ \\
\hline $0-23$ & 2 & 3 & 16 \\
$24-35$ & 7 & 9 & 52 \\
$36-60$ & 4 & 6 & 32 \\
Total & 13 & 18 & 7.75 \\
\hline
\end{tabular}

Table 3. Type of malnutrition at presentation among the study population to the hospital.

\begin{tabular}{|c|c|c|c|c|c|c|c|}
\hline \multirow[t]{2}{*}{ Type of Malnutrition } & \multicolumn{2}{|c|}{ No. of HIV + ve Children (\%) } & \multirow[t]{2}{*}{ Percentage $(\%)$} & \multicolumn{2}{|c|}{ No. of HIV - ve Children (\%) } & \multirow[t]{2}{*}{ Percentage $(\%)$} & \multirow[t]{2}{*}{ Total } \\
\hline & Males & Females & & Male & Female & & \\
\hline Marasmus & $6(19)$ & $9(29)$ & 48 & $20(5)$ & $37(10)$ & 15 & 72 \\
\hline Marasmic-Kwashiorkwo & $4(13)$ & $6(19)$ & 32 & $30(5)$ & $40(11)$ & 19 & 80 \\
\hline Kwashiorkwo & $3(10)$ & $1(3)$ & 13 & $32(8)$ & $55(15)$ & 23 & 91 \\
\hline Under Weight & 0 & $2(6)$ & 6 & $67(18)$ & $88(24)$ & 42 & 157 \\
\hline
\end{tabular}

Table 4. Percentage sero-positivity in the selected hospitals.

\begin{tabular}{|c|c|c|c|c|c|c|}
\hline $\mathrm{S} / \mathrm{N}$ & Selected Hospitals & No. of Samples & No. of Samples & Positive & Total & Percentage Sero-Positivity (\%) \\
\hline & & & Males & Females & & \\
\hline 1 & Aminu Kano Teaching Hospital & 40 & 4 & 7 & 11 & 22 \\
\hline 2 & Hasiya Bayero Pediatric Hospital & 100 & 5 & 5 & 10 & 10 \\
\hline 3 & Murtala Mohd Specialist Hospital & 50 & 2 & 3 & 5 & 10 \\
\hline 4 & General Hospital Wudil & 50 & 1 & 2 & 3 & 6 \\
\hline 5 & General Hospital Gaya & 50 & 1 & 0 & 1 & 2 \\
\hline 6 & General Hospital Gwarzo & 50 & 0 & 1 & 1 & 2 \\
\hline 7 & General Hospital Danbatta & 50 & 0 & & 0 & 0 \\
\hline
\end{tabular}


selected hospitals during the study. Aminu Kano Teaching Hospital had the highest seropositivity, 11 out of 50 samples accounting for $22 \%$ Hasiya Bayero Paediatric Hospital 10 out of 100 samples (10\%), Murtala Mo hammad Specialist Hospital, fives out of 50 (10\%), Wudil General Hospital three out of $50(6.0 \%)$, Gaya and Gwarzo General Hospitals, one each $(2.0 \%)$ and none recorded at Danbatta General Hospitals (0.0\%).

Table 5 below shows the commonest signs and symptoms with the sex distribution at presentation among the HIV positive children. Fever, cough and diarrhoea were the commonest symptoms while refusal of feed and vomiting were the least common. The commonest signs were oral candidiasis followed by lymphadenopathy and the least common sign was skin dyspigmentation.

Table 6 below illustrates the type of family setting of the HIV positive Children obtained from the study. $64.0 \%$ were found to be from the polygamous settings while $36.0 \%$ were from monogamous families. A chisquare test shows a significant association between polygamy and the incidence of HIV infection within the family $\chi^{2}=5.7, \mathrm{p}<0.01$.

Table 7 below shows the stage of HIV infection with the age distribution at presentation according to WHO paediatric HIV clinical staging. Majority presented at stage four $(64.5 \%)$ while $29 \%$ and $6.5 \%$ presented at stages three and two respectively.

Table 8 below shows relationship between type of malnutrition and severity of HIV infection. A chi-square

Table 5. Sign and Symptoms among the HIV positive children.

\begin{tabular}{|c|c|c|c|}
\hline Sign and Symptoms & Males (\%) & Females $(\%)$ & Total No. (\%) \\
\hline Oral Candidiasis & $10(32)$ & $11(35)$ & $21(67.7)$ \\
\hline Fever & $12(39)$ & $8(25)$ & $20(64.0)$ \\
\hline Cough & $12(39)$ & $5(16)$ & $17(54.8)$ \\
\hline Diarrhoea & $10(32)$ & $6(19)$ & $16(51.6)$ \\
\hline Skin Rash & $8(26.6)$ & $8(25)$ & $16(51.6)$ \\
\hline Ear Discharge & $8(25)$ & $7(22)$ & $15(48.3)$ \\
\hline Lymphadenopathy & $8(25)$ & $6(19)$ & $14(44)$ \\
\hline Hepatosplenomegally & $4(12.9)$ & $8(25)$ & $12(37.9)$ \\
\hline Oedema & $4(12.9)$ & $3(9.6)$ & $7(22.5)$ \\
\hline Parotids Swelling & $2(6.4)$ & $4(12.9)$ & $6(19.3)$ \\
\hline Skin Ulcers & 0 & $3(9.6)$ & $3(9.6)$ \\
\hline Refusal of Feeds & $1(3.2)$ & $2(6.4)$ & $3(9.6)$ \\
\hline Skin Dyspigmentation & 0 & $2(6.4)$ & $2(6.4)$ \\
\hline Vomiting & 0 & $2(6.4)$ & $2(6.4)$ \\
\hline
\end{tabular}

Table 6. Type of family settings among women whose children are HIV positive.

\begin{tabular}{cccc}
\hline Type of Family & $\begin{array}{c}\text { No. of HIV + ve } \\
\text { Children }\end{array}$ & $\begin{array}{c}\text { No. of HIV - ve } \\
\text { Children }\end{array}$ & Total \\
\hline Polygamous & 20 & 252 & 272 \\
Monogamous & 11 & 117 & 128 \\
TOTAL & 31 & 369 & 400 \\
\hline
\end{tabular}

$\chi^{2}=5.7, \mathrm{df}=1, \mathrm{p}<0.01$.

Table 7. W.H.O. paediatric HIV staging of children who were found to be positive. Age at presentation (years).

\begin{tabular}{ccccc}
\hline Clinical Staging & No. of Children (\%) & $<2$ & $2-3$ & $>3$ \\
\hline Stage 4 & $20(64.5)$ & 2 & 12 & 6 \\
3 & $9(29)$ & 2 & 3 & 4 \\
2 & $2(6.5)$ & 1 & 1 & 0 \\
\hline
\end{tabular}

Table 8. Relationship between type of malnutrition and severity of HIV infection at presentation.

\begin{tabular}{cccc}
\hline \multicolumn{2}{c}{ Severity of Malnutrition } & & \multicolumn{2}{c}{$\begin{array}{c}\text { Paediatrics HIV } \\
\text { Clinical Stages }\end{array}$} \\
\hline Type of Malnutrition & $\begin{array}{c}\text { Severe } \\
\text { (Stage 4) }\end{array}$ & $\begin{array}{c}\text { Less Severe } \\
\text { (Stage 2 - 3) }\end{array}$ & Total \\
Marasmus/Marasmic-Kwashiorkwo & 15,5 & 3,2 & 18,7 \\
Kwashiorkwo/Underweight & 2,2 & 1,1 & 3,3 \\
Total & 24 & 7 & 31 \\
\hline
\end{tabular}

$\chi^{2}=0.0003, \mathrm{df}=1, \mathrm{p} \leq 0.97$ (this is statically insignificant).

test of association indicates that there was no statistically significant association between the type of malnutrition and the severity of HIV infection. The chi-square value of 0.0003 was obtained and $p$ value was $<0.97$ at the degree of freedom of 1 .

\section{Discussion}

An HIV prevalence of $7.8 \%$ was found among malnourished children below the age of five years attending selected hospitals in Kano State. This figure is alarming considering the state wide HIV sero-prevalence data which shows steady decline over the years $4.9 \%$ in 2001 , $3.6 \%$ in 2003 and $3.4 \%$ in 2005 .

No previous studies, to the best of my knowledge, were available stating the national or state prevalence of HIV infection among paediatric age group with or without specific disease conditions. Most of the available studies were cross-sectional hospital based studies rather than multi-centered. Studies from Ogbomosho General Hospital South Western Nigeria and Aminu Kano Teaching Hospital North Western Nigeria reported 3.0\% and $23.3 \%$ as HIV sero-prevalence among malnourished 
children respectively [12]. Motayo et al., [13] reported a prevalence of $5.8 \%$ in children in Abeokuta South Western Nigeria. These findings correlate with the observed prevalence in the adult HIV/syphilis seroprevalence sentinel survey in those hospitals which recorded $1.3 \%$ and $4.3 \%$ for Ogbomosho General Hospital and Aminu Kano Teaching Hospital respectively (2005 HIV sentinel survey). The same survey reported state wide prevalence (for adults) in Oyo and Kano States as 1.8\% and 3.4\% respectively. If finding from this study is compared with the state prevalence quoted above, there is definite cause for concern; this finding being on the high side even though is less than what was reported from Aminu Kano Teaching Hospital in 2004 (23.3\%). It is also important to note that case detection in paediatric HIV shows real increase in prevalence rather than apparent increase since incubation period is short and case fatality is very high.

The high prevalence could be attributed to poor effort in the prevention of mother to child transmission services and the assumption that the epidemic has stabilized over the years as indicated by the 2005 sentinel survey might not be as real. In a similar study from rural South African Hospital, an age specific prevalence of $25.0 \%$ among 1 5 years age group was recorded [14]. This figure was much higher compared to our finding but is not unexpected considering the magnitude of the epidemic around the year 2000 in the South African nations.

It is important to note the degree of variation in the prevalence rates between urban and rural areas. It was observed according to 2005 sentinel survey that HIV prevalence was generally higher in urban than the rural sites even though this observation was not consistent across states.

In this study, the urban sites accounted for $6.5 \%$ while the rural sites accounted for only $1.2 \%$. There was also a wider variation even amongst the rural areas with Wudil (a town closest to Kano among all the study locations) accounting for the highest compared with other study locations in the rural areas. This degree of variation could not only be attributable to socio-cultural and economic reasons alone but could be largely due to high disparity in the provision of health care services between the two settings. In all the study locations, there were functional facilities for voluntary HIV testing and counseling provided by GHAIN. Unfortunately, about $75 \%$ health care resources both material and human are concentrated in the metropolitan. People in the rural areas will always have to come to the major hospitals in towns to attend to major health needs. Hence those HIV support services in the rural centers are poorly patronized and the services become grossly under utilized. This is especially so because HIV support and care services especially at entry point are not supposed to be accessed in isolation. It is therefore most likely that a significant number of children who tested positive to HIV are not residing in the areas where they receive care.

Findings from this study showed almost equal male to female ratio (M:F 1:1.3). The same was observed by workers in Jos North-Central, Nigeria [12] and also as reported in Ibadan by Babatunde et al., [15] although the prevalence was higher in the present study. Except in paediatric age group, most data suggest that HIV infection is commoner among females than males. Denis et al., [4] stated that females account for more than one half of all new cases in adolescents, and three quarters of new infections in adolescent females occur via heterosexual transmission.

Studies reported from Ife, South-Western Nigeria, showed more females than males while in another study from India there was a male preponderance [16]. Since behavioral factors do not come to play in paediatric HIV infection, gender variations most probably occur by chance.

Mode of transmission in all cases was vertical (mothers were sero-positive). This finding has contrasted most of the previous studies which recorded other minor routes of transmission. Workers in Abuja, the federal capital territory in 2006 reported blood transfusion and unidentified routes to have accounted for $4.6 \%$ and $2.3 \%$ respectively [8], while a similar retrospective study from Zaria in the same year showed blood transfusion accounting for $8.6 \%$ and unknown route $2.8 \%$ [6]. Denis et al., [4] reported that mother to child transmission accounted for up to $95.0 \%$ of paediatric HIV infection while other minor routes accounted for 5.0\%. Emeka et al., [17] reported higher prevalence of about $12 \%$ in children attending a treatment center in Oweri.

Vertical transmission accounting for all cases of HIV among the infected children is a positive indicator of an improvement on prevention through blood products or use of contaminated sharp objects. This preposition will be more glaring considering Emodi's report from Enugu (Eastern Nigeria) in 1998 where blood transfusion accounted for $68 \%$ of HIV infection in children. Additionally the age group under study is not exposed to other major means of contracting the disease like sexual promiscuity.

Two couples were found to be discordant. One had blood transfusion during a caesarian section to deliver the baby while the other who had two HIV positive twins had history of surgical procedure in a rural hospital one year prior to the delivery of the twins.

Fever, cough and diarrhoea were the predominant symptoms recorded in the study accounting for $64.5 \%$, $54.8 \%$ and $51.6 \%$ respectively. The signs and symptoms observed correlate with findings from a previous study at Aminu Kano Teaching hospital North Western Nigeria [10], except that a lesser number of children presented 
with diarrhoea in this study (51.6\%) compared to the previous one $(60.9 \%)$. This difference could be attributed to seasonal variation. Oral candidiasis and chest infection were the commonest conditions observed followed by diarrhoeal diseases, a finding similar to what was obtained from Zaria, North-western Nigeria [6]. Similarly in Enugu, Eastern Nigeria, children with oral candidiasis recorded the highest seropositivity followed by severe malnutrition [18]. In the Niger-Delta children with bronchopneumonia, septicemia and Pulmunary Tuberculosis had the highest incidence of HIV seropositivity [19]. In a similar hospital based cross-sectional study from India, the highest seropositivity rate $(25.0 \%)$ was reported among children with disseminated TB and chronic diarrhea [16]. From this data we can extrapolate the commonest pattern of opportunistic infections in our environment. Fungal infections rank the highest followed by bacterial infections most likely encapsulated Gram positive organisms like Streptococcus pneumoniae leading to chest infection.

Peak age of presentation was two to three years and this corresponds to the second category in the natural history of paediatric HIV infection which accounts for $50 \%-60 \%$ of the infected children. In the absence of treatment most of these children will die within this age bracket but with the introduction of antiretroviral therapy (ART) these children have the prospect of surviving to adolescence and beyond.

Children with marasmus accounted for $48.3 \%, 32.3 \%$ had marasmic kwashiokwor, while $12.9 \%$ and 6.5 presented with kwashiokwor and underweight respectively. There was no relationship between the type of malnutrition and the severity of HIV infection. This finding suggests that the clinician should suspect and screen for HIV when a child presents with malnutrition that does not respond to conventional therapy or when convalescence is very slow especially in a resource poor setting where routine screening is neither feasible nor affordable.

Polygamous family was the commonest type of family setting recorded among the HIV infected children accounting for $64.0 \%$ while monogamous family was only $36.0 \%$. From this data, a correlation has been established between polygamy and incidence of HIV in the family. Polygamy is an accepted tradition amongst people in the study area and HIV being a sexually transmitted disease, some forms of interventions may be necessary to address the issues within the context of legal and religious frame work.

Another point of concern is the age distribution of the HIV positive mothers in this study. Majority $18(58.0 \%)$ were between the age of $15-24$ years while the remaining $13(42.0 \%)$ were between the ages of $25-49$. This age bracket (15 - 24) is used as an index of estimating new infections. The implication is that with new infec- tions, the epidemic is not under control. Another obvious implication as it is observed from experience is that, these young women often lose their husbands at a later time due to AIDS and continue another life with other men in future thereby perpetuating the spread of the disease.

The most effective way to address the paediatric HIV pandemic is prevention of mother to child transmission and the knowledge of HIV status among pregnant women is crucial to the success of such prevention. This study further revealed that up to 17 women $(54.0 \%)$ whose children were HIV positive became aware of their HIV status as a result of this study while the rest 14 $(46.0 \%)$ were already aware. Amongst the 14 women, data for two on the knowledge of PMTCT was missing from the questionnaire and out of the remaining 12 , three $(25.0 \%)$ said they were informed of the prevention of mother to child transmission services and yet none of them cared to benefit from the services and they all delivered at home. The remaining nine (75.0\%) where not informed of PMTCT.

Voluntary counseling and testing is a prerequisite to enable women to access programme for prevention of mother to child transmission. Although there were centers for HIV voluntary testing and counseling in all the study locations, PMTCT services are not available at Gaya and Danbatta locations.

\section{Conclusions and Recommendations}

The result from this study reveals that about $7.8 \%$ of children attending selected hospitals in Kano with malnutrition are HIV positive. This confirmed that HIV/ AIDS epidemic in Kano is still a public health problem of enormous magnitude that deserves priority attention.

The commonest opportunistic infections observed from the study were chest infections and diarrhoeal diseases. There are still diagnostic difficulties in establishing pulmonary tuberculosis in children. However, children exposed to TB infected adults should be protected with isoniazid prophylaxis. A pneumococcal vaccine (including serotype 1 and 2) given to HIV-infected children in Soweto, South Africa, substantially decreased episodes of pneumonia and invasive bacterial diseases. Growth failure is a common feature in HIV-infected children and it is associated with early mortality. Adequate nutritional supplements with the locally available foods and prevention of micronutrients deficiency are equally important and they may serve to prevent frequent diarrhea seen in HIV infected infants. Additionally, maternal health and nutrition should be encouraged and basic hygiene education should be addressed.

The HIV prevalence within polygamous settings is increasing at an alarming rate. Cases for whereby an HIV positive second or third wife becoming source of infec- 
tion to the entire family are continuously reported, and these need to be addressed within the context of the laws that permit polygamy.

\section{REFERENCES}

[1] D. C. Douek, M. Roederer and R. A. Koup, "Emerging Concepts in the Immunopathogenesis of AIDS," Annual Review of Medicine, Vol. 60, 2009, pp. 471-484. http://dx.doi.org/10.1146/annurev.med.60.041807.123549

[2] R. A. Weiss, "How Does HIV Cause AIDS?" Science, Vol. 260, No. 5112, 1993, pp. 1273-1237. http://dx.doi.org/10.1126/science.8493571

[3] P. Andrew, T. Gareth, J. Prakash, B. Sandra and G. Philip, "International Perspectives, Progress and Future Challenges of Paediatric HIV Infection," Lancet, Vol. 370, No. 9581, 2007, pp. 68-80. http://dx.doi.org/10.1016/S0140-6736(07)61051-4

[4] T. Denis, K. Janet, M. Phillippa, E. Brian, N. Ruth, C. Hoosen, B. Raziya, M. Dorathy and P. Mary, In: Handbook on Paediatric AIDS in Africa, Revised Edition, 2006, pp. 213-216.

[5] A. Oniyangi, B. Awani and K. C. Iregbu, "The Pattern of Paediatric HIV/AIDS as Seen at the National Hospital Abuja, Nigeria," Journal of Clinical Practice, Vol. 9, No. 2, 2006, pp. 153-158.

[6] M. A. Bugaje and H. A. Aikhionbare, "Paediatric HIV/ AIDS Seen at Ahmadu Bello University Teaching Hospital Zaria, Nigeria," Annals of African Medicine, Vol. 5, No. 2, 2006, pp. 73-77.

[7] I. J. Emodi and G. O. Okafor, "Clinical Manifestations of HIV Infection in Children at Enugu, Nigeria," Journal of Tropical Paediatrics, Vol. 44, No. 2, 1998, pp. 73-76. http://dx.doi.org/10.1093/tropej/44.2.73

[8] G. N. Odaibo, D. O. Olaleye, L. Heyndrickx, K. Vereecken, K. Houwer and W. Jassens, "Mother-to-Child Transmission of Different HIV-1 Subtype among ARV Naïve Infected Pregnant Women in Nigeria," Journal of Tropical Paediatrics, Vol. 51, No. 3, 2005, pp. 145-147.

[9] G. Foster and J. A. Williams, "Review of Current Literature on the Impact of HIV/AIDS on Children in Sub-Saharan Africa," AIDS, Vol. 14, No. 3, 2000, pp. 275-285.

[10] S. I. Adeleke and Y. M Muktar, "Interactions of Child- hood Malnutrition and Human Immunodeficiency virus Infection in Sub Saharan Africa: Emphasis on Epidemiological, Immunological, Clinical and Preventive Modalities," Nigerian Journal of Clinical Sciences, Vol. 3, 2006, pp. 1-7.

[11] M. Cheesbrough, "District Laboratory Practice in Tropical Countries, Part 2," Cambridge University Press, Cambridge, 2002, pp. 248-266.

[12] S. I. Adeleke and Y. M. Muktar, "A Comparative Study of HIV Seroprevalence among Malnourished Children and Controls in Kano," Nigerian Journal of Pharmaceutical Medical Science, Vol. 1, 2004, pp. 23-26.

[13] R. M. Merchant and R. C. Shroff, "HIV Seroprevelance in Dessiminated TB and Chronic Diarrhea," Indian Paediatric Journal, Vol. 35, 1998, pp. 883-888.

[14] B. O. Motayo, U. Usen, B. O. Folarin, P. O. Okerentugba H. C. Innocent-Adiele and I. O. Okonko, "Prevalence and Seasonal Variations of HIV 1 and 2 Infection among Children in Abeokuta, South West Nigeria," Journal of Microbiology Research, Vol. 3, No. 3, 2013, pp. 107-110.

[15] S. D. Yeung, S. Wilkinson, C. F. Escott and F. Gilks, "Paediatric HIV Infection in a Rural South Africa District Hospital," Journal of Tropical Paediatrics, Vol. 46, No. 2, 2000, pp.107-110. http://dx.doi.org/10.1093/tropej/46.2.107

[16] O. O. Babatunde, E. O. Regina, J. B. Biobele and I. O. Kikelomo, "Prevalence and Clinical Pattern of Paediatric HIV Infection at the University College Hospital, Ibadan, Nigeria: A Prospective Cross-Sectional Study," Italian Journal of Pediatrics, Vol. 37, 2011, pp. 1824-7288.

[17] N. Emeka, M. Francis, E. Joseph and A. Paul, "Prevalence of Hepatitis B Co-Infection amongst HIV Infected Children Attending a Care and Treatment Centre in Owerri, South-Eastern Nigeria," The Pan African Medical Journal, Vol. 14, 2013, pp. 89-96.

[18] J. U. Ojukwu and C. N. Ogbu, "HIV Infection in Hospitalized Children with Endemic Diseases in Abakeleke, Nigeria: The Role of Clinically Directed Screening," Acquired Immuno Deficiency Syndrome Care, Vol. 19, No. 3, 2007, pp. 330-336.

[19] E. A. Daniel and O. E. Nelson, "Trend of HIV Seropositivity among Children in a Tertiary Institution in the Niger-Delta Region of Nigeria," Africa Journal of Health Sciences, Vol. 13, No. 1-2, 2006, pp. 80-85. 